\title{
Un marco ritual para la escena: el sacerdos histriónico en la palliata
}

Stella Maris Moro

Universidad Nacional de Rosario, Argentina

smmoro@yahoo.com.ar

\author{
María Eugenia Martí \\ Universidad Nacional de Rosario, Argentina \\ evgeny20@gmail.com
}

\section{Resumen}

En distintos pasajes de la palliata es posible leer indicios de las lógicas rituales que enmarcan los ludi scaenici. Ciertas máscaras remedan una auctoritas histriónica que permite dar curso al acontecimiento teatral mediante el poder de una parodia hilarante de la celebración del ritual. Esta capacidad de persuadir a los espectadores para entrar al espacio lúdico de la representación incluye también una demanda: silencio, atención y valoración ecuánime por parte de ellos. Actores y público se unen así como oficiantes y auxiliares del convivio teatral en un pacto de reciprocidad equitativa cuya relevancia es analizada en este artículo.

PALABRAS CLAVE: escena, ritual, aequum, ludi, palliata.

A ritual framework for the scene: the histrionic sacerdos in the palliata

\begin{abstract}
In different passages of the palliata it is possible to read indications of the ritual logics that frame the ludi scaenici. Certain masks mimic a histrionic auctoritas allowing the theatrical event to proceed through the power of a hilarious parody of the ritual celebration. This ability to persuade viewers to enter the
\end{abstract}


playful space of the performance also includes a demand: silence, attention and fair evaluation by their part. Actors and public join together to officiate and to assist in the theatrical convivium based in a pact of equitable reciprocity which relevance is analyzed in this article.

KEYWORDS: scene, ritual, aequum, ludi, palliata.

\title{
El marco ritual de la palliata: aura y performance
}

Una ineludible restricción subyace a cualquier aproximación al teatro antiguo: solo contamos con el acceso a versiones escritas tamizadas por siglos de transcripciones, correcciones y traducciones. Sin embargo, aunque un número significativo de los estudios sobre la palliata latina se focalicen en las particularidades de la trama, en realidad, las fabulae operan apenas como un sustrato del fenómeno total que constituyeron las puestas en escena en su contexto original:

\begin{abstract}
El problema de esta perspectiva de análisis es que pierde de vista el hecho de que el texto que hoy día leemos es el registro escrito de una pieza teatral que fue concebida para ser puesta en escena en el marco específico de los ludio juegos, ritual religioso colectivo, central en la religión romana. Fuera de ese ritual no había teatro público en Roma, por lo tanto, estudiar teatro romano implica tener en cuenta dicho contexto. (Vázquez, 2016:2-3)
\end{abstract}

El marco ritual y celebratorio de los ludi, fiestas que pertenecían al calendario oficial (Paoli, 2000:330-331), pone en relación el teatro con el culto romano (von Albrecht, 1994:112), es decir, con las festividades colectivas organizadas por el Estado y relevantes para la religión de Roma, e imprime sus particularidades a las posibilidades escénicas de la representación.

La lógica de todo ritual se manifiesta como una ofrenda que asciende desde el orden de los mortales en busca de una compensación divina y adquiere su efectividad en la repetición institucionalizada de actos y fórmulas verbales adecuadas a la función social del portavoz que ha sido revestido con el poder conferido por las instituciones (Bourdieu, 1985:69). Se trata, entonces, de una palabra autorizada, con fuerza performativa, que produce o realiza lo que nombra, pero no desde una voluntad individual:

(...) el poder de las palabras reside en el hecho de que quien las pronuncia no lo hace a título personal, ya que es solo su 'portador': el portavoz autorizado sólo puede actuar por las palabras sobre otros agentes y, a través de su trabajo, sobre las cosas mismas, en la medida en que su palabra concentra el capital simbólico acumulado por el grupo que le ha otorgado ese mandato y de cuyo poder está investido. (Bourdieu, 1985:69)

En este contexto, el oficiante se instituye como sacerdos, mediador a quien le ha sido dada la capacidad de transformar el espacio de co-existencia en un territorio simbólico del orden de lo sagrado y permitir, de este modo, la comunicación entre lo humano y lo divino:

Рага convertir a la bestia en "sagrada" hay que separarla del mundo de los vivos, es preciso que franquee ese umbral que separa los dos universos: es la meta de la ejecución. De ahí el valor, para nosotros tan profundo, del término 
sacerdos, que se apoya en *sakro-dhot-s, compuesto con ayuda de la raíz * dhe-, "hacer, poner", de donde "volver efectivo, realizar» (cfr. facio). El sacerdos es el agente del sacrificium, aquel que está investido de los poderes que le autorizan a "sacrificar". (Benveniste, 1983:350)

La capacidad performativa de la palabra ritual yace en la autoridad del portavoz, pero también está codificada en su iteración y se vuelve efectiva por la tradición que le permite realizarse. Adquiere eficacia como eco o cita de una palabra de la cual deriva y a la cual apela (Derrida, 1988:18). Más que acto deliberado, la performatividad propia del ritual es una práctica referencial mediante la cual el discurso produce los efectos que nombra (Butler, 1994:18).

Es cierto que el acontecimiento teatral (Dubatti, 2007:31), entre todas las formas de ars humana, persiste en su capacidad originaria de resistirse a la reproducción técnica, conserva su aura, la autenticidad del hic et nunc que hace a cada puesta en escena única e irrepetible (Benjamín, [1936] 2011:9-12). No obstante esta propiedad o quizá incluso gracias a ella, es decir, a su capacidad de actualizarse ritualmente, las comedias latinas resultaban legibles, efectivas en su recepción, en función de ser en realidad actos iterativos en relación dialógica (Bajtín, 1998:285ss.) con puestas en escena anteriores, ancladas en condiciones inherentes y contextuales específicas que permitían al público reconocer de modo inmediato personajes, lógicas de interacción y discursos sociales prototípicos, incluidos aquellos anclados en la religión.

Se trata, entonces, de un teatro sin prioridad mimética, en el cual la representación remeda las condiciones del ritual:

El teatro del juego, al contrario del teatro dramático, es una performance cuya finalidad no es representar una historia, sino celebrar ese ritual que los romanos llaman "juegos" (ludi). Así, una performance teatral romana se inserta ella misma en el tiempo ritual de los juegos y se adapta necesariamente a los valores de los juegos. Esto quiere decir que el marco ritual impone al espectáculo teatral las limitaciones específicas en relación con esos valores, y que es a partir de esos límites que podemos reconstituir el código, en otras palabras, el lenguaje espectacular de una performance cómica. (Dupont, 2007:191) $)^{1}$

Dupont señala dos momentos cruciales, la apertura y el cierre, como instancias respectivas de inicio y fin de una ceremonia que se da en el plano de la puesta en escena:

El prologusse dirige al público, interpelándolo en segunda persona del plural, para pedirle silencio. Este silencio es un preámbulo indispensable para todo ritual romano. En un sacrificio, es solicitado por la famosa fórmula "fauete lingua". En el teatro, la finalidad es transformar al público en auditoresespectadores, para que el ritual se pueda celebrar regularmente, lo que convierte a los espectadores en co-celebrantes de un ritual en el que la palabra es privilegio de los actores. (Dupont, 2007:194)

Como contrapartida, al final de la representación algún personaje concluye la ceremonia convocando al aplauso: 
A la apertura ritual del prólogo, corresponde un cierre ritual manifestado por los aplausos de los espectadores [...] Al silencio atento del prólogo corresponde, entonces, el estrépito de los aplausos. La iniciativa del ruido vuelve al público. Del mismo modo, solo una vez terminada la representación, los espectadores pueden levantarse. (Dupont, 2007:199)

Las máscaras que dan comienzo y final a la representación revisten el carácter de oficiantes en la ceremonia: reclaman para sí el poder de crear, a la manera del sacerdos, un espacio de expectación. Ya se trate de un dios o potencia divina como Mercurio en Amphitruo, Lar en Aulularia, la estrella Arturo en Rudens, la Lujuria (Trinnumus), de un servus (Miles) o simplemente un prologus (Casina, Poenulus, etc.), el personaje que inicia la obra se convierte en un sacerdos histriónico que instaura el silencio y la quietud que posibilitan el ritual en la escena. De la misma manera, las máscaras que invitan a los aplausos al final de las obras señalan el regreso a la lógica del ruido que marca el final de la ceremonia. Más allá del rol que desempeñen dentro de los acontecimientos de la fabula, unos y otros asumen la función de brindar el marco de posibilidad a la escena, ya que esta no podría desenvolverse sin que ellos, desde la instancia de la actio, determinen sus condiciones mismas de existencia.

Así como en el ritual el oficiante es depositario de un poder delegado por el Estado y, por tanto, se constituye en intercesor entre dioses y hombres, la máscara que posibilita el inicio del espectáculo hereda este poder en el contexto de la puesta en escena. En sus dicta asume de manera paródica los códigos propios de la representación ritual y los traslada al ámbito de la dramatización lúdica:

No obstante es preciso tener en cuenta que el ludus, como ritual, instaura, según señalan Dupont y Letessier (2011:13ss.), un tiempo-espacio por fuera de la vida cívica y política, imponiendo a los participantes una distensión social incompatible con toda actividad seria. Los juegos no son una institución cívica, sino una fiesta pública. (Vázquez, 2016:7)

En este contexto, la auctoritas que porta el sacerdos proviene del marco institucional de los $l u d i$, que recubre de validez el acto, y de su calidad de portavoz de los discursos oficiales del Estado que sostiene y financia las representaciones. Sin embargo, esa autoridad es también revalidada en el convivio teatral, que posee un carácter eminentemente transaccional, de acuerdo con uno de los rasgos invariables que Dubatti le atribuye a estos espacios de encuentro:

El convivio implica la reunión de dos o más hombres, vivos, en persona, en un centro territorial, encuentro de presencias en el espacio y convivencia acotada -no extensa- en el tiempo para compartir un rito de sociabilidad que se distribuyen y alternan dos roles: el emisor que dice-verbal y no verbalmenteun texto, el receptor que lo escucha con atención. (Dubatti, 2003:13)

En este sentido, sería viable hipotetizar que una condición preliminar para la celebración del rito teatral supondría que el intercambio entre cavea y scaena se desarrolle de modo equitativo, a través de un juego transaccional que posibilite la performance efectiva.

De este modo, la risa hallaría su sitio en los ludi justamente porque mantiene y no transgrede la matriz discursiva que sostiene todo ritual:

La mayor parte de las condiciones necesarias para que un enunciado performativo tenga éxito se reducen a la adecuación del locutor -o, mejor 
dicho, a la adecuación de su función social-al discurso que pronuncia: cuando no se pronuncie por una persona que tenga el "poder" de pronunciarlo o, en general, cuando "personas o circunstancias particulares" no sean "las convenientes para que pueda invocarse el procedimiento en cuestión", en suma, cuando los locutores no tienen autoridad para emitir las palabras que enuncian, el performativo está condenado siempre al fracaso. Pero lo más importante es, tal vez, que el éxito de esas operaciones de magia social que son los actos de autoridad o, lo que viene a ser lo mismo, los actos autorizados, está subordinado a la reunión de un conjunto sistemático de las condiciones interdependientes que componen los rituales sociales. (Bourdieu, 1985:71)

Se trata, entonces, de la traslación del poder performativo de la palabra del oficiante al actor en la puesta en escena, de modo paródico y con vistas a la comicidad. Esta palabra performativa, desde su dimensión persuasiva, hará posible la expectación. Los espectadores acceden a suspender la gravedad del ritual religioso para conceder a ciertas máscaras, durante el espacio y tiempo restringido del convivio, la facultad de oficiar como sacerdotes histriónicos, capaces de abrir y cerrar el ritual de intercambio escénico o remedar augurios.

En el breve espacio de este trabajo, analizaremos algunos ejemplos de esta transposición en la palliata.

\section{Intermediarios entre dioses y hombres: lo aequum como condición del ritual}

Según se ha visto hasta aquí, del mismo modo como en el ritual se atribuye al sacerdos la autoridad en tanto que propiciador e intérprete de los designios divinos, en la comedia se instaura un espacio discursivo de intermediación entre actores y espectadores. Las condiciones de posibilidad de este territorio dependerán de la capacidad que exhiban aquellos a los que se reviste de esa autoridad histriónica, para mantener la equidad entre ofrendas y favores, temores y resguardos.

Entre las máscaras de la palliata que asumen el rol de prologar la obra, el caso de Mercurius $^{2}$ en Amphitruo constituye un ejemplo singular. Mensajero entre los dioses, asume en la obra explícitamente un doble papel de intermediario: en el convivio teatral y desde el prólogo, como transmisor de la voluntad de Júpiter hacia los espectadores; en la fabula, como cómplice que, mientras vigila apostado en las puertas de palacio, evita que su padre Iuppiter sea descubierto y se interpone a la llegada de Sosia. De esta forma, Mercurius se ubica siempre balanceando la relación entre el orden divino y humano y se constituye así en el sacerdos histriónico por excelencia, al producir esa transfiguración escénica que mantiene inalterable su matriz de rasgos constitutivos en ambas dimensiones del hecho teatral (convivio y fabula): intermediación, reciprocidad y ecuanimidad.

En Amphitruo, la reciprocidad transaccional se proyecta como un rasgo isotópico en diferentes planos discursivos (dicta), tanto como en los ámbitos de acción (acta) de esta máscara.

2 En adelante, Mercurius y Iuppiter, en cursiva, refieren a los personajes de la comedia; Mercurio y Júpiter, en redonda, hace alusión a los respectivos dioses de la mitología griega. 
Los primeros quince versos del prólogo se destacan por una condensada sucesión de paralelismos: los lexemas tejen un equilibrio que se proyecta referencialmente hacia la esfera de lo humano (el comercio), en acciones ("emundis vendundisque"), localizaciones ("peregrique et domi"), materias ("res rationesque"), temporalidades ("quasque incepistis res quasque inceptabitis"), preanuncios y efectos ("nuntiis... et lucro"). En la dimensión sintáctica, la relación entre hombres y dioses se manifiesta comparativamente en perfecta igualdad y equilibrio: "ut... ut... ita... itaque..." [Pl. Amph. 13-16].

La construcción de una relación de equidad entre dioses y hombres aparece una y otra vez en el corpus de la palliata. Cualquier transgresión a esta norma es considerada monstruosa y punible con la muerte, tal como se deduce de los dicta de Lycus, en Poenulus. Este leno, que ha denostado como ineficaces [vv.449ss.] los sacrificios a Venus (a la que tilda de "avarae Veneri", 458) y otros dioses (que califica como "avidi", 461) y despreciables los consejos del arúspice ("non homo trioboli", 463), se declara merecedor del peor de los castigos: Lycus: "... nunc ibo, amicos consulam, quo me modo / suspendere aequom censeant potissimum." (794-795) [... ahora iré, consultaré a mis amigos, de qué modo consideran equitativo por sobre todas las cosas que yo me cuelgue.]

Casi al final de esta comedia, el senex Hanno alcanza la reposición del mos maiorum al proclamar la necesidad de retribuir equitativamente y con gratitud las acciones de los dioses:

HANNO: (...) quod boni mihi di danunt, vobis vostraeque matri, eas dis est aequom gratias nos agere sempiternas, quom nostram pietatem adprobant decorantque di immortales.

(Pl. Poen. 1253-1255)

HANNO: (...) lo que conceden de bueno los dioses a mí, a ustedes y a la madre de ustedes, es equitativo que nosotros les demos estas gracias eternas a los dioses, ya que los dioses inmortales aprueban y honran nuestra obediencia.

Paralelismos como estos son un recurso habitual en la palliata: ya se ha mencionado ampliamente en la crítica (por ej. Duckworth, 1952) el uso de dobles (mellizos, personajes que se contraponen) y de tramas duplicadas de forma casi arquitectónica (Clark, 1976); podríamos agregar una extensa lista de frases, a la manera de los versos 466 y 795 del leno Lycus citados más arriba, que constituyen una repetición invertida. A partir de su presencia isotópica, podría plantearse, entonces, que estos paralelismos irían más allá de un mero artificio lingüístico, discursivo o dramático y permitirían poner de manifiesto la centralidad del concepto de 'equidad' en la matriz discursiva de la comedia latina. Lo aequum está presente en diversos tipos de relaciones, ya sea filiales (como inherente a la pietas) o de amistad (como consecuencia lógica del principio de fides), posee prevalencia en los contratos matrimoniales y meretricios (sea desde su sostenimiento, sea en su ruptura). En los ejemplos aquí propuestos, reaparece demarcando las restricciones en las que la comunicación entre dioses y hombres resulta posible. En el ritual, el sacerdos garantiza que la respuesta divina sea proporcional al temor humano. En la representación teatral, el rol de sacerdos histriónico parece encarnar lo aequum, como Mercurius en Amphitruo, o sancionar la transgresión, como señala Lycus, profeta frustrado de la inequidad. 


\section{Construcción discursiva del poder del sacerdos histricus}

El sacerdos es depositario de un poder que le conceden las instituciones religiosas y la creencia social, una autoridad que lo reconoce como portador y reproductor de la palabra divina, que le permite convertirse en intercesor entre los dioses y los hombres. Del mismo modo, el prologus y el cantor reclaman a los espectadores para sí esa auctoritas en el marco de la lógica retórica de captación del público. En efecto, en los dicta de Poenulus de Plauto, el personaje Prologus construye su autoridad como parodia de Aquiles cuando declara citar un texto de Aristarco:

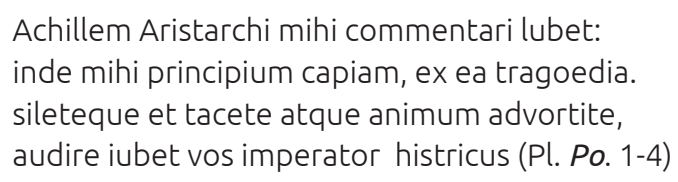

Me agrada evocar el Aquiles de Aristarco; de allí, de esa tragedia, tomaré el principio: "Hagan silencio y cállense y presten atención: les ordena oír el general histriónico".

El cambio de tonalidad por la abrupta irrupción del adjetivo histricus transfigura la escena trágica en el contexto cómico. Sin embargo, el personaje ya ha asumido la auctoritas suficiente como para pronunciar, entre promesas y amenazas, una larga cadena de mandatos a cada sector de la cavea acerca de cómo comportarse y dónde sentarse (5-43), sin que falte la solicitud de ánimo imparcial ("animo aequo", 22; "ne... iniuria", 37) a la hora de premiar la representación. Este extenso pasaje de mandatos, en el que predominan los imperativos y subjuntivos yusivos, cierra con el refuerzo de este poder que ha reclamado para sí el personaje y que el público ha concedido durante el hic et nunc de la puesta escénica: "haec quae imperata sunt pro imperio histrico" (44) [estas cosas que son ordenadas por la autoridad histriónica].

Dupont (2007:198-9) comenta este pasaje destacando la constitución de ese poder que ejerce magnéticamente el actor sobre sus espectadores, de los cuales exige la entrega de todos sus sentidos, a través de una figura retórica vecina del oxímoron, que, lejos de autodestruirse, se refuerza en el marco de los ludi scaenici:

\footnotetext{
Imperio histrico: la fórmula se destruye a sí misma. El imperium es ese poder supremo con el cual están revestidos los magistrados y que los convierte en la "ley viviente", según palabras de Cicerón. El imperator es el inverso absoluto del histrión, que no tiene ningún poder para ordenar lo que sea. Pero la destrucción misma de esta fórmula de autoridad establece lo que exige. Pues el histrión en escena tiene un poder: hacer reír a los espectadores, forzarlos a entrar, por medio de sus chistes, en el espacio lúdico del cual él es el dueño. Es este poder el que le permite abrir los juegos escénicos.
}

Ahora bien, si bien este poder se instala aquí a partir del lenguaje militar ("imperio"), no obstante se reviste progresivamente de un valor procedente de otros discursos sociales, como aquel propio del ritual religioso. Según Dupont (2007:194-195):

Durante el prólogo, los espectadores son increpados a través de los imperativos "cállense", "préstenme atención", "asístanme", "síganme" o "ayúdenme", expresiones todas que pertenecen a la lengua técnica de los 
cultos y por medio de las cuales quien oficia solicita la ayuda de los otros celebrantes.

De este modo, con el recurso de la utilización de fórmulas rituales tales como favete lingua y plaudite, estos personajes se arrogan paródicamente el rol de intermediarios entre actores y espectadores, a la manera en que el sacerdos reclama para sí el espacio de expectación necesario para la ceremonia que va a emprender. De hecho, tanto en el ritual religioso como en el escénico se produce el acontecimiento espectacular (Dubatti, 2007). El espacio de la expectación se constituye en la otredad que supone el escenario y su dinámica: solo existe teatralidad a partir de esta función receptiva derivada de la separación de roles y espacios entre los oficiantes del ritual: histriones y espectadores (Pricco, 2006:363). De esta manera, la distribución espacial en el convivium (Dubatti, 2007) permite también adoptar roles de participación en el ritual escénico. En ambos casos, el silencio es condición para que la expectación tenga lugar.

La presencia de fórmulas rituales permite, entonces, leer la palliata como una parodia que re-presenta el discurso oficial del poder: si no hay silencio, no hay representación, de modo tal que la auctoritas encuentra su proyección ficcional en el marco de lo histriónico.

Hecyra de Terencio pone en escena claramente este proceso. La construcción del silencio precede necesariamente a la representación y ese espacio se instancia a partir de la fórmula ritual del favete lingua: Prologus: "Mea causa causam accipite et date silentium." (Ter. Hec. 55) [Por mi causa, adopten esta causa y hagan silencio]. Al tomar sus lugares, los miembros del populus se convierten en adiutores:

Eam calamitatem vestra intellegentia

Sedabit, si erit adiutrix nostrae industriae (31-32)

La comprensión de ustedes mitigará esta calamidad si actúa como favorecedora y ayudante de mi obra.

[...] facite ut vestra auctoritas

Meae auctoritati fautrix adiutrixque sit. (47-48)

Hagan que la autoridad de ustedes sea favorecedora y ayudante de mi autoridad.

El sacerdos encuentra auxiliares entre los espectadores, quienes deberán colaborar en el ritual ("adiutrix") con su silencio y atención ("fautrix", de faveo, una vez más, favete lingua). Los versos citados proyectan en la organización sintagmática el intercambio paralelístico entre sacerdos y adiutores: a "nostra industria" corresponde "vestra intelligentia", a "mea auctoritas", "vestra auctoritas". En el ritual escénico, el sacerdos histriónico tiene, en el marco de la representación, el poder de establecer el orden, el silencio, la atención; por su parte, al transformarse de pueblo en audiencia, al tomar posesión de un lugar que lo convierte en partícipe del ritual escénico, el espectador recibirá la autoridad para decretar el éxito o el fracaso de la performance:

(...) Nunc turba nulla est: otium et silentium est:

Agendi tempus mihi datum est: vobis datur

Potestas condecorandi ludos scenicos (43-45) 
Ahora no hay ningún bullicio, hay ocio y silencio; a mí me concedieron el tiempo de actuar, a ustedes les otorgan el poder de premiar las representaciones.

\section{Adivinos paródicos: el hariolus de comedia}

Analizamos hasta aquí el modo como ciertos personajes de la palliata se construyen como sacerdotes en el marco de la representación.

Dada la importancia que tenían las supersticiones en la cultura latina, es esperable que, en el contexto de los ludi, los discursos sociales referidos a estas prácticas encontraran también su lugar. En cierta forma, al igual que la parodia de ceremonias rituales, la presencia en la comedia de alusiones a escenas de adivinación y revelaciones oníricas estarían alineadas con el proceso de romanización de los originales griegos en función, siempre, de una mejor empatía con el público.

En Epidicus, por ej., el servus callidus se presenta interpretando sus propios augurios: "liquido exeo foras auspicio, avi sinistra;" (Pl. Ep. 182) [salgo con augurio favorable: con un ave desde la izquierda]. El esclavo interpreta el vuelo de las aves a la manera de un verdadero adivino.

Ahora bien, no es este el único caso. Asinaria aporta mayor evidencia respecto de cómo se cruzan estos discursos en la palliata. En primer lugar, los dos esclavos de la obra, Libanus y Leonida, se identifican como sendas divinidades: Salus y Fortuna, en relación con los bienes que han conseguido para su amo, es decir, las monedas necesarias para contratar a la meretrix (712-719). Por otra parte, el nombre Libanus encierra un doble sentido (López López, 1991:115): ante todo se trata de un gentilicio, utilizado de manera frecuente para referirse a algún esclavo, tal vez en función de su origen, pero al mismo tiempo, libanus hace referencia al incienso, hierba utilizada en los rituales religiosos. Este último rasgo podría estar en correlación, tal como afirma López López (ib.), con el hecho de que este esclavo exige a su amo honores propios de una divinidad:

(...) Si quidem mihi statuam et aram statuis

atque ut deo mi hic immolas bovem: nam ego tibi Salus sum.

(Pl. As. 712-713)

(...) Por cierto, si me levantás una estatua y un altar y me inmolás un buey acá, como si fuera un dios, porque para vos yo soy Salud.

Sin embargo, también puede estar asociado con otros pasajes de la obra donde el esclavo actúa como oficiante de un ritual de adivinación. Indeciso respecto de qué rumbo darle a la acción, Libanus se presenta en escena con un monólogo que incluye un pasaje adivinatorio:

(...) unde sumam? quem intervortam? quo hanc celocem conferam?

impetritum, inauguratumst: quovis admittunt aves,

picus et cornix ab laeva, corvos parra ab dextera

consuadent; certum herclest vostram consequi sententiam.

sed quid hoc, quod picus ulmum tundit? non temerariumst.

certe hercle ego quantum ex augurio eius pici intellego,

aut mihi in mundo sunt virgae aut atriensi Saureae. (258-264) 
(...) ¿De dónde voy a sacar? ¿A quién voy a despojar? ¿Hacia dónde voy a llevar este bote? Se ha consultado, ha sido augurado: por donde quiera las aves admiten, el pájaro carpintero y la corneja desde la izquierda, el cuervo y la parra por la derecha. Por Hércules, se ha decidido seguir el consejo de ustedes. Pero... ¿qué hay? ¿Por qué el pájaro carpintero golpea el olmo? No es casualidad. Por Hércules, ciertamente, por lo que yo comprendo del augurio de este pájaro carpintero, o habrá varas para mí en el mundo, o para el conserje Sáureas.

El servus desarrolla en estos versos su labor de hariolus y se arroga la capacidad de comprender ("intellego") los designios del vuelo de las aves y de sus acciones. Poco después corrobora el augurio y certifica su don adivinatorio:

Ergo mirabar quod dudum scapulae gestibant mihi, hariolari quae occeperunt, sibi esse in mundo malum. (315-316)

Como dije, me asombraba de que hace un rato se sacudían mis espaldas, que comenzaron a adivinar que había una desgracia para ellas en el mundo.

En esta secuencia, el servus se define como hariolus, adivino. Ha asumido un nuevo rol paródico dentro de la comedia. El final de la representación dará por concluido también ese ludus, cuando el anciano sea el verdadero objeto del castigo a manos de su mujer engañada (909ss.).

\section{El equilibrio como condición del pacto espectatorial}

En vistas de lo planteado hasta el momento, puede considerarse que el intercambio que se da en el espacio del convivium entre scaena y cavea está regido por las convenciones performativas del ritual pero también por el principio estructural del equilibrio y la equidad. En Amphitruo, por ejemplo, este pacto se explicita cuando se declara necesaria e indispensable una transacción equitativa entre los dones divinos y las ofrendas mortales:

MERCURIUS. haec ut me voltis adprobare adnitier,

[lucrum ut perenne vobis semper suppetat]

ita huic facietis fabulae silentium

itaque aequi et iusti hic eritis omnes arbitri. (Pl. Am.13-16)

MERCURIUS: como quieren que yo apruebe estas cosas, que me esfuerce para que el lucro perpetuo sea siempre suficiente para ustedes, así hagan silencio para esta comedia, y así todos serán árbitros justos y equitativos.

El verso 16 presenta a Mercurius exigiendo a los espectadores ser árbitros "aequi et iusti". En el comercio entre dioses y hombres, ambas condiciones son necesarias: aquellos dan favores, lo cual es de por sí justo, atento al derecho divino y, a cambio, en la misma exacta medida (ita...ut), estos les retribuyen con respeto. Los vv. 33 al 36 reiteran esta lógica de paralelismos, que comporta una equidad entre los términos, los versos, las estructuras sintácticas, y los referentes:

MERCURIUS.: iustam rem et facilem esse oratam a vobis volo, nam iusta ab iustis iustus sum orator datus.

nam iniusta ab iustis impetrari non decet, 
iusta autem ab iniustis petere insipientia est; (33-36)

MERCURIUS: quiero que se les pida una cosa justa y fácil, pues he sido otorgado por justos como embajador justo de cosas justas. Pues no conviene solicitar cosas injustas de los justos, pero es ignorancia pedir cosas justas de los injustos.

mientras el verso siguiente cierra la secuencia con una definición de iniqui: "quippe illi iniqui ius ignorant neque tenent." (37) [por cierto, aquellos inequitativos ignoran y no sostienen el derecho]. La coexistencia de ambos términos revela una diferencia semántica: el equilibrio entre dar y recibir y el respeto por el derecho son complementarios y no se conciben separadamente.

En Hecyra volvemos a encontrar esta lógica transaccional, ya no mediatizada por un dios, sino trasladada a la máscara prologus que oficia ahora de sacerdos. El pacto espectatorial solo logrará sustanciarse si el equilibrio rige el intercambio entre el ofrecimiento histriónico y la atención receptiva: "Prol. Nunc quid petam mea causa aequo animo attendite." (Ter. Hec. 28) [Ahora escuchen con ánimo equitativo qué pido por mi causa], es decir, con una disposición de ánimo equivalente a lo que por derecho merezco en función de lo que he dado.

A la puesta en escena, corresponde una retribución equivalente: un juicio libre de intereses ajenos a la representación, es decir, que el espíritu con que se va a presenciar la obra no responda a causas que provengan de otra cosa que la representación misma.

Los adversarios rompen el equilibrio actor-espectador:

PROLOGUS. Sinite impetrare me, qui in tutelam meam

Studium suum et se in vestram commisit fidem,

Ne cum circumventum inique iniqui irrideant. (52-55)

PROLOGUS: Permitan que yo consiga que, quien encomendó su dedicación a mi tutela y a sí mismo a la lealtad de ustedes, no lo rodeen con sus burlas los inequitativos de manera inequitativa.

En estos versos, "inique" e "iniqui" señalan la ruptura de la lógica de intercambio: los espectadores carecen de fides, no porque hayan quebrado una ley -no interviene la noción de ius en este contexto lúdico-, sino porque no retribuyen equitativamente a la actuación, y por tanto rompen con la norma consuetudinaria de toda transacción.

Tal como sintetizan Caballero de del Sastre y Schniebs (2001:7):
la fides atraviesa todos y cada uno de los aspectos que hacen a la organización social de Roma, desde las relaciones interpersonales (...) hasta la práctica jurídica, la militar, la religiosa y la política. (...) En razón de ello, fides se asocia a menudo con términos propios de la esfera moral (dignitas, decus, gloria, etc.), jurídica (iustitia, aequitas, etc.), religiosa (religio, pietas).

La fides es una presencia necesaria en el pacto de intercambio de la escena, debe regir el comportamiento de los involucrados, como se señala en el Prólogo de Casina:

Salvere iubeo spectatores optumos,

fidem qui facitis maxumi, et vos Fides. (Pl. Cas. 1-2) 
Deseo saludarlos, los mejores espectadores, que tienen en más alta estima a la Lealtad, y la Lealtad a vosotros.

En el acontecimiento espectacular, la fides exige equilibrio entre el dar y el recibir, condición de posibilidad del pacto de expectación. Esta doble operatoria equitativa se establece en la medida en que se asienta sobre una lógica de poder: al actor, con poder para convocar el silencio del público, se corresponde un público con poder para consagrar el éxito de la obra o desaprobarla. Quebrantar este equilibrio puede llevar a excesos que resulten monstruosos, es decir, que señalen los límites de lo debido.

\section{Máscaras, roles paródicos y discursos sociales}

Como se ha planteado hasta aquí, la equidad constituye, en el marco de la sociedad romana, la condición de inteligibilidad de las transacciones sociales. A su vez, este equilibrio restablece el objetivo último del ritual lúdico: la búsqueda de sostenimiento o restitución del equilibrio social.

En el ámbito de la comedia, las máscaras que asumen el rol de oficiantes, ya sea como sacerdotes o como harioli, sostienen estos valores a pesar de e incluso dentro del contexto paródico. Este equilibrio se logra mediante un intercambio regido por la fides y la aequitas entre la divinidad receptora de la ofrenda y los mortales que buscan su retribución. La efectividad de la performance ritual lúdica está dada por un marco iterativo tradicional que permite la concreción de un pacto de mutuo y equitativo beneficio. La lógica de pacto equitativo de intercambio se reitera en la dinámica escénica ya que resulta fundamental una clara distribución de espacios y roles para que tenga lugar la expectación. Como los oficiantes del ritual a la divinidad, histriones y auditorio se recubren de una autorictas ritual al ocupar sus espacios. Solamente en el momento en que el actor se apropia de la palabra cómica y del ámbito de la acción histriónica y es retribuido equitativamente con el silencio y la atención del auditorio, la escena existe, se realiza performativamente. 


\section{Q Bibliografía}

\section{Fuentes}

》 Leo, F. (1985). Plauti Comoediae. Berlin: Weidmann.

» St. John Parry, E. (1857). Publii Terentii Comoediae. London: Whitaker and Co.

\section{Estudios}

» Bajtín, M. (1998 [1979]). “El problema de los géneros discursivos". En: Estética de la creación verbal. México: Siglo XXI, 248-293.

" Benjamin, W. (2011). La obra de arte en la era de su reproducción técnica. Fehrman, S. (trad.). Buenos Aires: El cuenco de plata.

» Benveniste, E. [1969] (1983). Vocabulario de las instituciones indoeuropeas. Madrid: Taurus.

" Butler, J. [1993] (2008). Cuerpos que importan. Barcelona: Paidós.

» Bourdieu, P. (1985). “El lenguaje autorizado: las condiciones sociales de la eficacia del discurso ritual”. En ¿Qué significa hablar? Barcelona: AKAL, 67-77.

»Caballero de del Sastre, E.; Schniebs, A. (comps.) (2001). La fides en Roma. Aproximaciones. Buenos Aires: UBA.

»Clark, A. (1976). "Structure and symmetry in the Bacchides of Plautus", TAPhA 106, 85-96.

"Derrida, J. (1988). "Signature, event, context". En: Graff, G. (comp.) Limited Inc. Evanston: Northwestern University Press, 1-23.

"Dubatti, J. (2007). Filosofía del teatro I. Convivio, experiencia, subjetividad. Buenos Aires: Atuel.

»Dubatti, J. (2003). El convivio teatral: Teoría y práctica del Teatro Comparado. Buenos Aires: Atuel.

" Duckworth, G. (1952). The nature of Roman comedy. Princeton: Princeton University Press.

» Dupont, F. (2007). Aristote ou le vampire du théâtre occidental. Paris: Flammarion.

» Dupont, F.; Letessier, P. (2011). Le théâtre romain. Paris: Armand Colin.

» Grimal, P. (1981). La civilisation romaine. Paris: Flammarion.

"López López, M. (1991). Los personajes de la comedia plautina: nombre y función. Lleida: Pagès Editors.

" Martí, M. E.; Moro, S. M. (2017). "Un episodio 'débil' de Asinaria de Plauto: humor y captatio escénica”. En: Coria, M.; Martí, M. E.; Moro, S. M. (eds.) Tránsitos, pasajes y cruces en las teatralidades del mundo. Rosario: Universidad Nacional de Rosario Ateacomp, 237-247. En https://ateacomp.files.wordpress.com/2017/08/transitospasajes-y-cruces-en-las-teatralidades-del-mundo1.pdf; obtenido el 16/12/19. 
" Moro, S. M.; Martí, M. E. (2018). "La dinámica de las transacciones en el teatro plautino: un análisis de lo aequum en Amphitruo y Poenulus", SAGA 8, 350-376.

» Moro, S. M.; Martí, M. E. (2016). "La construcción de la civitas en la dinámica del intercambio: una lectura desde la Asinaria de Plauto". En: Ruiz de los Llanos, N.; M. Rubio, M.; Rieszer, C. (comps.), XXIII Simposio Nacional de Estudios Clásicos. Ciudadanía y poder político en el mundo clásico. Debates y proyecciones. Actas. Salta: Universidad Nacional de Salta y Asociación Argentina de Estudios Clásicos, 275-280.

» Moro, S. M.; Martí, M. E. (2014a). "La instauración del espacio ritual en los ludiscaenici. Hecyra entre lo aequum y lo iniquum". En: Assis, E.; Lobo, C.E. (comps.), Significación y Resignificación del mundo clásico antiguo: Actas XXII Simposio Nacional de Estudios Clásicos, Vol. 2. Tucumán: Universidad Nacional del Tucumán, 682-687.

" Moro, S. M.; Martí, M. E. (2014b). "Equidad y transacción en el teatro plautino". En: Quiroga, C. (comp.), Actas del V Congreso Argentino internacional de Teatro Comparado Teatro Latinoamericano y Teatro del Mundo. Buenos Aires: Leviatán, 290300.

" Paoli, U. (2000). Urbs. La vida en la Roma antigua. Farran y Mayoral, J. y Natividad Massanes (trads.). Barcelona: Iberia.

»Pricco, A. (2006). "Teatralidad cognitiva y teatralidad psicofísica en el discurso terenciano: la constitución del auditorio". En: Pociña, A.; Rabaza, B.; Silva, M. (eds.) Estudios sobre Terencio. Granada: Universidad de Granada, 357-371.

"Vázquez, R. (2016). "Agite ite foras: ferte pompam (St. 683). Stichus de Plauto y la escenificación del ritual". Phaos 16, 1-19.

» von Albrecht, M. (1994). Historia de la Literatura Romana. Vol I. Barcelona: Herder. 